\title{
D E Space-A Realistic Measure of Changes in Arch Morphology: Space Loss Due to Unattended Caries
}

\author{
WILLIAM M. NORTHWAY* and ROBERT W. WAINRIGHT
}

St. Bruno, Quebec, Canada; and Center for Human Growth and Development, The University of Michigan, Ann Arbor, Michigan 48109

J Dent Res 59(10):1577-1580, October 1980

\section{Introduction.}

The principal studies on the subject of arch length change, probably more accurately defined as arch depth change, have used the following definition of arch length: the perpendicular distance from the most labial surface of the central incisor to the line joining the distal surfaces of the deciduous molars or second premolars. ${ }^{1-3}$ While accurately describing changes in total arch length (depth), this measurement is influenced by a number of events occurring simultaneously, and hence loses descriptive value for some important specific changes within the arch. Clinch underscored such influences with the observation that flaring and later uprighting of anterior teeth accounted for large changes in arch length. He suggested that this measure should therefore be referred to as the external arch length. ${ }^{1}$

Moreover, early studies using calipers, brass wires, and mathematic equations have not lent themselves readily to longitudinal studies, since without an anatomical reference point, it has not been feasible to accurately quantify directions of change. The concept described here has been tailored to portray the volatile changes occurring in the buccal segments during the mixed dentition. It has been named D E Space and has been defined as the distance between the mesial midpoint of the first permanent molar (or in its absence, the distal midpoint of the second primary molar, or second premolar) and the distal midpoint of the canine (or the mesial midpoint of the first primary molar, or first premolar in its absence) (see Fig. 1).

Received for publication August 2, 1979 Accepted for publication September 24, 1979

*Present address: 12776 West Bay Shore Drive, Traverse City, MI 49684
This paper explores the dimensional changes of the dental arch which take place in the presence of unattended dental caries by monitoring changes in D E Space.

\section{Materials and methods.}

The utilization of the concept D E Space has been made possible through use of the Optocom, an instrument capable of registering numerous coordinates in three dimensions on a set of study casts within an accuracy of $0.2 \mathrm{~mm} .{ }^{4}$ The reproducibility of D E Space among 225 paired recordings was found to have a standard deviation of $0.255 \mathrm{~mm}$. All registrations are relative to the occlusal plane, and a point on a given tooth can be compared from year to year, relative to the occlusal projection of that point as determined by the palatal rugae points. Numerous earlier works have advocated the use of palatal rugae as a reference in surveying dentitional changes from year to year. ${ }^{5-8}$ The data for Standards of Human Occlusal Development were all compiled in this fashion. ${ }^{9}$ Part of the working mechanism of the Optocom is an articulating device which allows the mandibular cast to be oriented in occlusion relative to the maxilla, and hence to the palatal rugae. This presents a particularly effective method of monitoring positional changes occurring within either dental arch.

One hundred seven children were selected from the growth sample at the Centre de Recherche sur la Croissance Humaine at the Université de Montréal. Data on these individuals were collected annually and longitudinally for an average of $5.9 \mathrm{yr}$, starting at age six. Quadrants unaffected by caries or premature extractions of primary molars for the duration of the study were placed into the control group, Caries-free. Those who developed caries or had restorations placed at any time during the study are listed throughout according to their status of maximum severity. Severe caries was dif- 
ferentiated from mild caries according to the degree of anatomical destruction as seen on the study casts. The sexes were pooled and justification presented earlier. ${ }^{10}$

\section{Results.}

One-way analyses of variance were performed at each age, and attained significance levels are listed with the sample sizes on the table at the bottom of the figures (see Figs. 2 and 3).

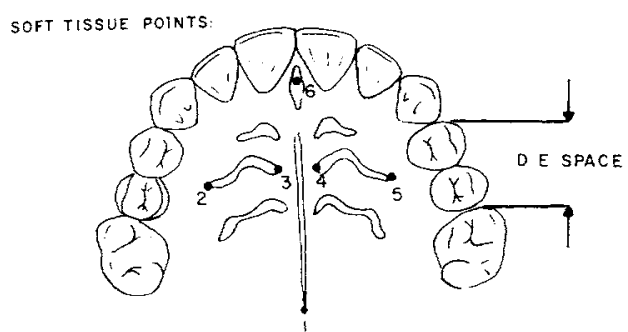

Fig. 1 - Palatal rugae points from which dental cast orientation can be performed, also, representation of D E Space.
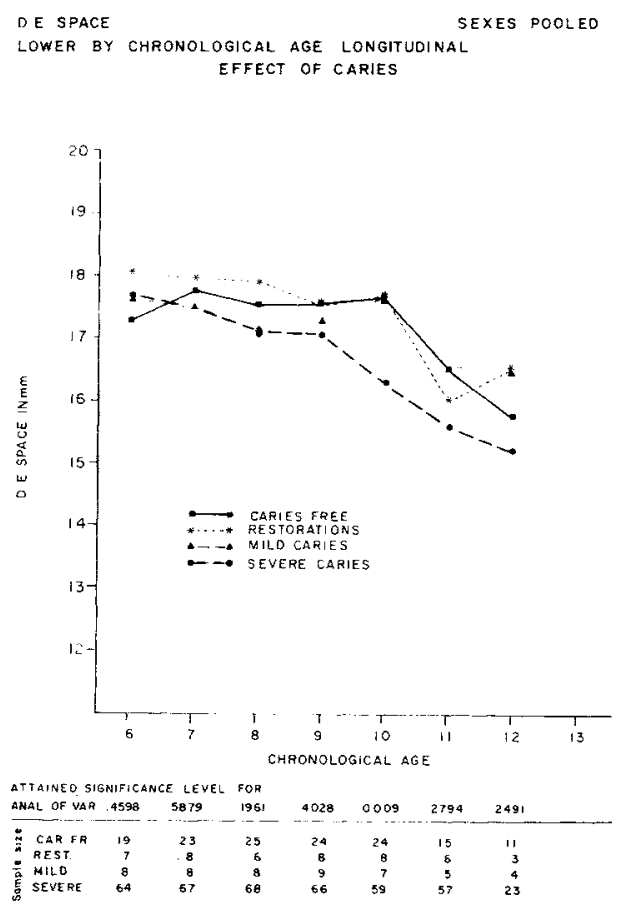

Fig. 2

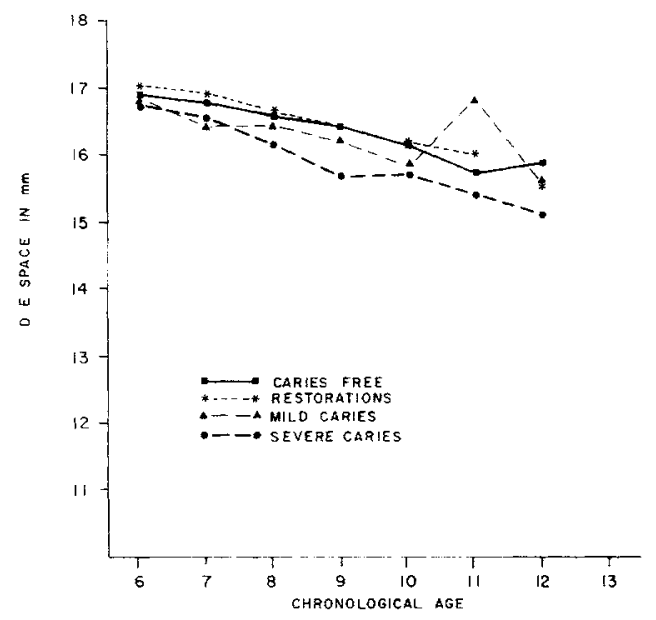

\begin{tabular}{|c|c|c|c|c|c|c|c|}
\hline $\begin{array}{l}\text { ATTAINEO SI } \\
\text { ANAL OF VAR }\end{array}$ & 7881 & 3471 & $\begin{array}{l}\text { FOR } \\
\text { OSZ4 }\end{array}$ & 0019 & 2858 & $\cos 39$ & 2492 \\
\hline$\cong$ CAR FR & 49 & 58 & 54 & 53 & 47 & 38 & 19 \\
\hline REST. & 13 & 12 & 11 & 12 & 12 & 10 & 5 \\
\hline MILD & 5 & 6 & 5 & 7 & 7 & 7 & 4 \\
\hline SEVEAE & 72 & 77 & 80 & Bi & 70 & 71 & 41 \\
\hline
\end{tabular}

Fig. 3

For the mandibular data, the only significant finding was a difference in $\mathrm{D} E$ Space at age ten $(F=5.94 * * *) .^{\dagger}$ The Severe Caries Group had a significantly reduced D E Space and was the only group which varied significantly from the others. Student's $t$ tests for comparisons with Severe Caries yielded $t$ statistics as follows: $2.50^{*}$ for the Caries-free, $2.14^{*}$ for the Restorations Group, and $2.66^{* *}$ for Mild Caries.

For the maxillary groups, a difference in $D E$ Space was found at age nine $(F=$ $\left.5.21^{* * *}\right)$. Again, it was the D E Space for the Severe Caries Group that was significantly reduced from the others. Values for $t$ tests were $3.89 * * *$ with the Caries-free and 2.59* with the Restorations Group; there were no significant differences from the Mild Caries Group. There was also a significant difference at age eleven $\left(F=2.62^{*}\right)$. Here the only two groups which varied significantly from one another were the Mild and Severe

$\dagger$ All asterisks refer to statistics in the table. 
Caries $\left(t=2.54^{*}\right)$. There was an unusual elevation in the value for Mild Caries in this year, and the borderline level for the $F$ value confirms the likelihood of normal variability.

In both arches, the Severe Caries Group maintained a D E Space $0.5-1.0 \mathrm{~mm}$ shorter than the Caries-free Group for the duration of the study, but only in the above cited years were there significant differences.

A comparison of the mean ages of exfoliation of primary molars revealed a significant difference between the Caries-free and Severe Caries Groups in both arches and for both primary molars (see statistics in table below).

\section{Discussion.}

Using D E Space to examine the effects of dental caries on arch morphology, the data were viewed by chronological age with the sexes pooled. It was found that $D E$ Space for the Restorations and Mild Caries Groups behaved similarly to the Caries-free Group at all ages. The only carious group

\begin{tabular}{|c|c|c|c|c|c|}
\hline \multicolumn{6}{|c|}{$\begin{array}{c}\text { TABLE } \\
\text { COMPARISON OF MEAN AGES OF } \\
\text { EXFOLIATION BETWEEN CARIES-IREE } \\
\text { AND SEVERE CARIES GROUPS }\end{array}$} \\
\hline & & & $\begin{array}{l}\text { Caries- } \\
\text { free }\end{array}$ & $\begin{array}{l}\text { Severe } \\
\text { Caries }\end{array}$ & $\begin{array}{c}t \\
\text { Statistics }\end{array}$ \\
\hline \multirow[t]{2}{*}{ Upper: } & $\mathrm{D}$ & $\begin{array}{c}\overline{\mathrm{X}} \\
\text { s.d. } \\
\mathrm{N}\end{array}$ & $\begin{array}{c}116.78 \\
16.51 \\
68\end{array}$ & $\begin{array}{c}109.78 \\
19.24 \\
55\end{array}$ & $2.17^{*}$ \\
\hline & E & $\begin{array}{c}\bar{X} \\
\text { s.d. } \\
\mathrm{N}\end{array}$ & $\begin{array}{c}123.36 \\
19.43 \\
61\end{array}$ & $\begin{array}{c}112.11 \\
17.80 \\
36\end{array}$ & $2.84^{* *}$ \\
\hline \multirow[t]{2}{*}{ Lower: } & D & $\begin{array}{l}\bar{X} \\
\text { s.d. } \\
\text { N }\end{array}$ & $\begin{array}{c}118.44 \\
13.83 \\
36\end{array}$ & $\begin{array}{c}109.65 \\
15.55 \\
57\end{array}$ & $2.77^{* *}$ \\
\hline & $\mathrm{E}$ & $\begin{array}{c}\bar{X} \\
\text { s.d. } \\
\text { N }\end{array}$ & $\begin{array}{c}127.68 \\
17.41 \\
37\end{array}$ & $\begin{array}{c}113.71 \\
15.28 \\
38\end{array}$ & $3.69 * * *$ \\
\hline
\end{tabular}

Those children with unattended severe caries lost their affected primary molars(s) nearly one year early. Those cases whose succedaneous teeth did not also come early would have been excluded from this data. Any individual who was missing a tooth for two or more consecutive recordings fell into the category of premature loss, and the values were treated with those of that group. which differed significantly from the Cariesfree population was Severe Caries. At age nine in the upper, and age ten in the lower, the Severe Caries Group underwent a reduction in D E Space that caused it to differ significantly from the other groups. Interestingly, there was also found to be a significant difference between the Severe Caries and the Caries-free Groups in terms of the age at which the primary molars were exfoliated. Since the mean age for the loss of primary molars was one year earlier in the Severe Caries Group, it was judged that the phenomenon of sustained severe decay caused these primary molars to exfoliate and hence be replaced nearly one year prematurely. Some of the leeway shift took place earlier for this group than for the Cariesfree, thus explaining the reduction in $D E$ Space.

Fanning et al. have noted a hastened replacement of primary teeth in cases where the pulps have been removed, 1-15 and certainly a similar phenomenon is in operation here, but our findings demonstrate that the acceleration is a function of the pathology, not of the treatment. The material from this sample also corroborates Breakspear's contention that an average space loss of $1 \mathrm{~mm}$ due to dental caries occurs. ${ }^{16-17}$ The mean for our Severe Caries Group was $0.5-1.0 \mathrm{~mm}$ shorter than that of the Cariesfree Group for both arches. We cannot, however, agree with Jarvis, who wrote that the occurrence of dental caries posed the same threat to arch length as the loss of a primary molar. ${ }^{18}$

Finally, the size of D E Space reduction attributable to severe caries is similar to the amount of divergence that could be introduced by sexual dimorphism. But since the numbers of males and females are almost equal for each age in the Severe Caries Group, the observed difference cannot be attributed solely to the compounded effect of gender.

\section{Summary.}

By using only a portion of the dental arch, rather than some geometric construction that conforms to the dental arch, more pertinent information can be gathered regarding the sequelac of some event or insult to the arch. The measurement, D E Space, has been explained and utilized to describe 
the effects of unattended dental caries on arch form. Only caries which become severe have a significant effect on the dental arch a reduction in $\mathrm{D}$ E Space, which can be interpreted as relative arch length (depth) and is significant only for the year after its exfoliation. This occurs one year early and is also significant.

\section{Acknowledgments.}

The authors wish to acknowledge Dr. Arto Demirjian, Centre de Recherche sur la Croissance Humaine, Université de Montréal; Dr. Robert Moyers, Center for Human Growth and Development, University of Michigan; and Dr. Frans van der Linden, Department of Orthodontics, University of Nymegen for their invaluable contributions.

\section{REFERENCES}

1. CLINCH, L.M.: An Analysis of Serial Models Between Three and Eight Years of Age, Dent Rec 71:61-72, 1951.

2. HURME, V.O.: Standards of Variation in the Eruption of the First Six Permanent Teeth, Child Devel 19:213-231, 1948.

3. MOORREES, C.F.A.: Dentition of the Growing Child, London: Oxford Press, 1959.

4. VAN der LINDEN, F.P.G.M.; BOERSMA, H.; ZELDERS, T.; PETERS, K.A.; and RAABEN, J.H.: Three Dimensional Analysis of Dental Casts by Means of the Optocom $J$ Dent Res 51:1100, 1972.

5. FRIEL, E.S.: Migrations of Teeth Following Extraction, Proc Roy Soc Med 38:456$462,1945$.

6. LEBRET, L.: Growth Changes of the Palate, $J$ Dent Res 41:1391-1404, 1962.

7. PEAVEY, D.C. and KENDRICK, G.S.: The Effects of Tooth Movement on the Palatine Rugae, $J$ Prosthet Dent 18:536-542, 1967.
8. VAN der LINDEN, F.P.G.M.: An Investigation on the Use of Palatal Rugae for the Registration of Anterior-posterior Changes in the Position of Buccal Teeth, Amer Board of Orthodont, 1974, Thesis.

9. MOYERS, R.E.; VAN der LINDEN, F.P.G.M.; RIOLO, M.L.; and MCNAMARA, J., Jr.: Standards of Human Occlusal Development, Ann Arbor, MI: University of Michigan Press, 1976.

10. NORTHWAY, W.M.: Antero-posterior Arch Dimension Changes in French-Canadian Children: A Study of the Effects of Dental Caries and Premature Extractions, Montréal, Quebec: Université de Montréal, 1977, Thesis.

11. FANNING, E.A.: Longitudinal Study of Tooth Form and Root Resorption, New Zealand Dent $J$ 57:202, 1961.

12. FANNING, E.A.: Effect of Extraction of Deciduous Molars on Formation and Eruption of Their Successors, Angle Orthodont $32: 44,1962$.

13. CHARBENEAU, G.T.: A Bitewing Radiographic Study of some Problems Related to Space Management in the Posterior Segments of the Primary and Mixed Dentitions, $J$ Dent Child 17:14-19, 1950.

14. LAUTERSTEIN, A.M.; PROZANSKY, S.; and BARBER, T.K.: Effect of Deciduous Mandibular Molar Pulpotomy on the Eruption of Succedaneous Pre-molars, J Dent Res 41:1367-1371, 1962 .

15. SCHACHTER, H.: The Incidence and Effect of Premature Extraction of Deciduous Teeth, Brit Dent J 75:57-61, 1943.

16. BREAKSPEAR, E.K.: Further Observations on Early Loss of Deciduous Molars, Dent Pract 11:233-252, 1961.

17. BREAKSPEAR, E.K.: Sequelae of Early Loss of Deciduous Molars, Dent Record 71 : 127-134, 1951.

18. JARVIS, A.: The Role of Dental Caries in Space Closure in the Mixed Dentition, Toronto, Ontario: University of Toronto, 1952, Thesis. 